\title{
Implementação de Sistemas Municipais de Ensino: entre Condições Locais e Expectativas de Desenvolvimento Educacional
}

\author{
Ledriana Minusculi Panis \\ Universidade do Oeste de Santa Catarina - SC, Brasil. \\ ledripanis@htmail.com \\ Elton Luiz Nardi \\ Universidade do Oeste de Santa Catarina - SC, Brasil. \\ elton.nardi@unoesc.edu.br
}

Educação: teoria e prática, Rio Claro, SP, Brasil - elSSN: 1981-8106

Está licenciada sob Licença Creative Common

\section{Resumo}

O trabalho tem por objetivo analisar a correspondência entre condições locais de organização e implementação de Sistemas Municipais de Ensino (SME) e expectativas de desenvolvimento educacional nutridas por governos municipais. Aborda o papel do município e sua autonomia legal para institucionalizar o sistema próprio de ensino e tece reflexões sobre perspectivas de desenvolvimento educacional. Tendo como campo empírico um conjunto de municípios da mesorregião Oeste do estado de Santa Catarina, e tomando por base documentos normativos da educação desses municípios, bem como resultados de questionários submetidos aos seus dirigentes municipais de educação, sublinha que a implementação dos SME é interferida por fatores locais e externos de importante repercussão nos municípios. Conclui, realçando a possibilidade de os municípios trilharem um caminho de transformação da realidade local, de modo a promover maior compasso entre a organização e implementação dos seus sistemas de ensino e as expectativas de desenvolvimento educacional.

Palavras-chave: Sistema Municipal de Ensino. Condições locais. Desenvolvimento educacional.

\section{Implementation of Municipal Teaching Systems: between Local Conditions and Educational Development Expectations}

\author{
Abstract \\ The aim of this paper is to analyze the correspondence between local conditions of \\ organization and implementation of Municipal Teaching Systems (MTS) and \\ expectations of educational development supported by the municipal government. It \\ deals with the role of the city and its legal autonomy to institutionalize its own \\ teaching system and reflects perspectives on the educational development. Having as
}


an empiric field a set of cities of the west region of Santa Catarina state and based on normative documents of education from these cities and questionnaires subjected to the city educational leaders, it emphasizes that the implementation of the MTS is interfered by local and external factors of important repercussion in the cities. We concluded highlighting the possibility that the cities follow the path of transforming the local reality in order to promote a bigger line between the organization and the implementation of their teaching systems and the educational development expectations.

Keywords: Teaching Municipal System. Local condition. Educational development.

\title{
Implementación de Sistemas Municipales de Enseñanza: entre Condiciones Locales y Expectativas de Desarrollo Educacional
}

\begin{abstract}
Resumen
El trabajo tiene como objetivo analizar la correspondencia entre condiciones locales de organización e implementación de Sistemas Municipales de Enseñanza (SME) y expectativas de desarrollo educacional nutridas por los gobiernos municipales. Aborda el papel del municipio y su autonomía legal para institucionalizar el sistema propio de enseñanza y teje reflexiones sobre las perspectivas de desarrollo educacional. Teniendo como campo empírico un conjunto de municipios de la mesorregión oeste del estado de Santa Catarina, y tomando como base documentos normativos de la educación de esos municipios, así como resultados de cuestionarios sometidos a sus dirigentes municipales de educación, subraya que en la implementación de los SME interfieren factores locales y externos de importante repercusión en los municipios. Concluye realzando la posibilidad de que los municipios hagan un camino de transformación de la realidad local, a modo de promover un mayor compás entre la organización y la implementación de sus sistemas de enseñanza y las expectativas de desarrollo educacional.
\end{abstract}

Palabras clave: Sistema Municipal de Enseñanza. Condiciones locales. Desarrollo educacional.

\section{Introdução}

Inaugurado pela Constituição de 1988, o atual modelo federativo do Brasil ascendeu o município à condição de ente da federação, entidade com autonomia política, administrativa e financeira, com capacidade de auto-organização e atribuições no provimento de políticas públicas. 
Ao município também foi creditado o direito de organização do sistema próprio de ensino ${ }^{1}$, ainda que, no princípio, essa possibilidade tenha sido questionada. ${ }^{2}$ De acordo com Saviani (1999), a ambiguidade herdada da Constituição de 1988 foi superada com a promulgação da nova Lei de Diretrizes e Bases da Educação Nacional (LDB), Lei $\mathrm{n}$ 0 9.394, de 20 de dezembro de 1996, ao estabelecer, no Artigo 8, que "a União, os Estados, o Distrito Federal e os Municípios organizarão, em regime de colaboração, os respectivos sistemas de ensino" (BRASIL, 1996).

Saviani (1999) anota, ainda, que apesar de a LDB definir o caráter opcional de organização dos Sistemas Municipais de Ensino (SME), estão claras as competências e responsabilidades dos municípios na organização de seus sistemas. Conforme lemos no parágrafo único do art. 11 da LDB, além da organização dos sistemas próprios, os municípios podem optar por se integrar ao sistema estadual de ensino ou mesmo compor com ele um sistema único de educação básica.

Sobre as possibilidades que têm os municípios, e com base nas disposições contidas no Parecer CNE/CEB no 30/2000, temos que toda e qualquer escolha eleita por eles não se dá "sem a existência prévia do sistema municipal de ensino, o reconhecimento da autonomia do município e de um regime de colaboração." Isto porque se trata da existência constitucional do sistema municipal, cabendo sua organização aos municípios. Tanto a organização quanto o modo de funcionamento submetem-se à autonomia destes entes federativos, "obedecendo ao princípio da colaboração recíproca e das normas gerais da lei de diretrizes e bases da educação nacional" (BRASIL, 2000, p.6).

Considerando o quadro de atribuições e responsabilidades conferidas aos municípios, impõe-se a reflexão sobre o significado e o lugar dos sistemas municipais no contexto nacional. Seguindo Sarmento (2005, p. 1384), cabem questionamentos

\footnotetext{
${ }^{1}$ O Parecer CNE/CEB no 30/2000 define sistema de ensino como: “Conjunto de campos de competências e atribuições voltadas para o desenvolvimento da educação escolar que se materializam em instituições, órgãos executivos e normativos, recursos e meios articulados pelo poder público competente, abertos ao regime de colaboração e respeitadas as normas vigentes" (BRASIL, 2000, p. 13).

2 Ocorre que "na Constituição Federal não aparece a expressão os respectivos sistemas de ensino, mas os seus sistemas de ensino" (SAVIANI, 1999, p. 122).
} 
como: "com o atual quadro da globalização e do federalismo vigente no país, como ficam realmente as possibilidades democráticas? Quais os riscos da fragmentação?"

Apesar das incertezas e dificuldades enfrentadas por muitos municípios na organização e implementação de seus SME, o fato é que muitos foram institucionalizados ${ }^{3}$ desde a atual LDB.

Atentos a esse fenômeno e às possibilidades dele decorrentes, o presente trabalho tem por objetivo analisar a correspondência entre condições locais de organização e implementação dos SME e expectativas de desenvolvimento educacional nutridas por governos locais.

Em vista desse propósito, a delimitação do campo empírico compreendeu um conjunto de municípios da mesorregião Oeste do estado de Santa Catarina, cujos sistemas de ensino foram institucionalizados a partir da vigência da atual LDB. ${ }^{4}$ Para fins de representação, foram considerados 40 municípios distribuídos nas áreas de abrangência de três microrregiões, identificadas pelas respectivas associações de municípios: Associação dos Municípios do Alto Irani (Amai); Associação dos Municípios do Noroeste Catarinense (Amnoroeste); e Associação dos Municípios do Oeste de Santa Catarina (Amosc).

A estratégia metodológica comportou o exame das leis que institucionalizaram os sistemas de ensino nos municípios amostrados, bem como a aplicação de questionários direcionados aos respectivos dirigentes municipais de educação.

Consoante o objetivo declarado, iniciamos pela apresentação de reflexões acerca do papel dos SME e de perspectivas de desenvolvimento educacional a eles associadas. Na sequência, atentos ao objetivo do trabalho, são abordadas condições locais de organização e implementação dos sistemas de ensino dos municípios pesquisados, bem como expectativas de desenvolvimento educacional nutridas pelos

\footnotetext{
${ }^{3}$ A associação dos termos organização e implementação é aqui compreendida como processo de institucionalização dos sistemas, ou seja, processo que lhe dá caráter institucional. Já a constituição dos sistemas municipais coube à Constituição Federal de 1988, que, por sua vez, não os instituiu em seu modus operandi, assim como não estabeleceu prazos para isso.

${ }^{4} \mathrm{O}$ estudo constitui desdobramento de uma pesquisa de mapeamento da gestão educacional no âmbito de SME, a qual contou com o apoio da Fundação de Amparo à Pesquisa e Inovação do Estado de Santa Catarina (Fapesc).
} 
governos municipais com a institucionalização desses sistemas. Por fim, são tecidas considerações finais nascidas do entrecruzamento dos achados da pesquisa e das reflexões de base.

\section{Sistemas municipais de ensino e desenvolvimento educacional}

A partir da Constituição de 1988, os municípios foram reconhecidos como entidades autônomas, agora entes federativos. Com essa ascensão veio, também, a instituição dos SME e, segundo Boaventura (1997), do ponto de vista educacional, uma das maiores inovações à esfera do poder local: o estabelecimento de normas pedagógicas.

Ao confirmar a existência dos SME, a LDB ainda preserva certa cautela com relação à sua organização, dando a possibilidade ao município de organizá-lo ou de integrar-se ao sistema estadual de ensino, compondo um sistema único de educação básica, o que não enfraquece, segundo Saviani (1999), a norma constitucional.

Atento ao conteúdo da LDB, Cury (2008, p. 1201) sublinha que

nos artigos 11 e 18, em consonância com o artigo 211 da Constituição Federal, [a LDB] reconhece, explicitamente, os sistemas municipais de ensino e esclarece suas incumbências em matéria de educação escolar. Entre estas está a de autorizar, credenciar $e$ supervisionar os estabelecimentos do seu sistema de ensino (Grifos do autor).

A mesma linha segue o Parecer CNE/CEB no 30/2000 que, consoante a lei nacional, registra a importância da "institucionalização efetiva de sistemas municipais de ensino cujo funcionamento possa beneficiar os níveis de ensino próprios da sua autonomia e competência" (BRASIL, 2000, p. 14).

Sob esse ângulo, entendemos que a possibilidade de os municípios organizarem seus sistemas de ensino concorda com o propósito de efetivação de um projeto educacional local, com o qual possam protagonizar avanços almejados para o setor, em favor de toda população. 
Por considerarmos que um sistema educacional é muito mais do que o traçado de regras e princípios educacionais, na medida em que pressupõe consciência e intencionalidade (SAVIANI, 2000), as ações implicadas não se baseiam apenas na ideia de unir e articular, mas de agir com organização, tendo em vista o alcance de resultados. Nesse sentido, entendemos que a institucionalização dos SME é medida que reclama condições locais, considerada a articulação entre concepções, estruturas administrativas, normas, redes, professores, projeto político-pedagógico e alunos (ROMÃO, 2010).

Sob o ângulo da superação de modelos da gestão centralizadora, podemos dizer que a LDB reconhece no município uma instância pública próxima do cidadão, realçando a tese de que essa esfera possui melhores possibilidades de atender aos anseios da comunidade local.

Azevedo e Santos (2012, p. 554), em estudo sobre as influências do poder central no planejamento da educação de municípios, anotam que "as cidades têm sido consideradas como o espaço que detém as condições de ser a sustentação do exercício da cidadania, da aceitação das diferenças, do multiculturalismo, da participação cidadã, do exercício da fraternidade e da solidariedade." No entanto, as cidades não deixam de ser lugar de práticas competitivas, de desconfiança, individualismo, enfim de exclusão, cujas tentativas de superação "demandam a articulação das relações sociais segundo uma perspectiva solidária e integrada aos espaços locais."

Em síntese, se por um lado as dificuldades frequentemente enfrentadas pelos municípios têm sido relacionadas a questões de ordem financeira e à série de encargos e responsabilidades atribuídos a essa esfera ao longo do tempo, por outro segue projetada a valorização dos espaços municipais, que, comumente, está associada a iniciativas que despontam em diversos municípios brasileiros, dentre as quais podemos apontar a organização dos sistemas próprios de ensino.

Atentas essa questão, Werle, Thum e Andrade (2010, p. 386) assinalam, a partir de estudo sobre municípios gaúchos, que as leis de SME têm expressado de forma mais explícita "temas da gestão democrática, da valorização do magistério, da ação redistributiva, do planejamento municipal de educação e da atenção a peculiaridades 
locais." Nessa direção, os SME tornam-se "construções sociais que os municípios instituem a partir da confluência de uma multiplicidade de forças, incluindo as sociais, as políticas, as institucionais e as culturais dentre outras" (WERLE; THUM; ANDRADE, 2010, p. 378). Na esteira desse entendimento, diferentes aspectos sinalizam para o favorecimento da atuação do município no campo educacional.

Um desses aspectos diz respeito à possibilidade de redução de estruturas complexas e de fortalecimento da autonomia da escola. Outro aspecto é a existência da vinculação de recursos mínimos à manutenção e desenvolvimento do ensino, pois os municípios, conforme observa Romão (2010), salvo poucas exceções, são mais vulneráveis do ponto de vista financeiro, o que torna a vinculação de recursos um mecanismo valioso para a garantia dos investimentos, ainda que caibam reservas acerca dos mecanismos de subvinculações, como a política de fundos.

Substituído pelo Fundo de Manutenção e Desenvolvimento da Educação Básica e de Valorização dos Profissionais da Educação (Fundeb), instituído em 2007, o Fundef sedimentou tendências que vinham se esboçando há décadas, qual seja, a da descentralização dos encargos educacionais relativos à escolaridade obrigatória. Em outras palavras, é ampliado o papel do poder local no que se refere à oferta de serviços (VIEIRA, 2011, 128).

O dever municipal com a oferta da educação e a gestão autônoma desse setor é outro aspecto decisivo à atuação dos municípios. Definidas as competências e responsabilidades municipais na oferta e gestão da educação, fortalecem-se as bases do direito à educação pela via do dever do Estado. Trata-se de um avanço na medida em que as opções municipais poderiam, quando a critério exclusivo dos gestores públicos, submeterem-se a interesses estranhos à coletividade.

Outro aspecto a ser destacado é o regime de colaboração entre os sistemas de ensino, previsto no art. 211 da Constituição Federal e reforçado na LDB, em seu artigo 8‥ Desde a Carta Magna, o regime de colaboração foi definido como mecanismo de apoio entre os entes federativos na definição e implementação das políticas educacionais, com vistas à viabilização da educação de qualidade (AZEVEDO; SANTOS, 2012). Também questionado por se realizar "em meio a um contexto no qual a translação de responsabilidades tem levado não à cooperação, mas a um quadro de 
concorrência entre os entes federados [...]" (SOUZA; RAMOS; DELUIZ, 2007, p.41), há consenso entre educadores e especialistas da área sobre a necessidade de aperfeiçoamento desse mecanismo.

Por fim, considerando que a organização e implementação de um sistema próprio de ensino pode melhor corresponder à realidade local, destacamos a necessidade de uma maior integração das políticas sociais, com a qual seja possível construir maior unidade na ação pública e, não menos importante, suplantar a já conhecida e onerosa sobreposição de programas governamentais.

Considerados esses aspectos, que a nosso ver são representativos da afirmação dos municípios, afirmação essa fortalecida pelo desempenho dos SME, vemos projetada a necessidade de reflexões acerca do que, efetivamente, tem favorecido ou dificultado a organização e implementação desses sistemas. Este é o foco das reflexões que apresentamos na próxima seção, com base nos achados da pesquisa.

\section{Condições locais e os sistemas de ensino}

A mesorregião Oeste de Santa Catarina é formada por 118 municípios. É conhecida pelo seu potencial ligado à industrialização de alimentos e pela qualidade do solo, de onde sai boa parte da produção nacional de grãos, aves e suínos.

As três microrregiões que constituem o campo empírico da pesquisa, identificadas pelas respectivas associações de municípios - Amai, Amnoroeste e Amosc - compreendem um conjunto de 40 municípios, a massiva maioria com população inferior a 10.000 habitantes.

Em relação aos SME, 92,5\% dos municípios das microrregiões pesquisadas já os institucionalizaram. ${ }^{5}$ Dentre estes, 43,2\% o fizeram entre os anos de 1997 e 1999 e outros $24,3 \%$ a partir do ano de 2008 .

\footnotetext{
${ }^{5}$ Dados registrados até maio de 2011.
} 
Coerentes com a determinação constante na LDB, todos os sistemas cujas leis foram examinadas são compostos por instituições e órgãos municipais de educação e por instituições privadas de educação infantil. As principais incumbências conferidas ao SME e que, portanto, implicam estas instituições e órgãos, estão dispostas no Quadro 1.

\begin{tabular}{|c|c|c|c|c|}
\hline Principais incumbências & mai & $\begin{array}{l}\text { Amn } \\
\text { oroeste }\end{array}$ & mosc & otal \\
\hline $\begin{array}{l}\text { Organizar, manter e desenvolver os } \\
\text { órgãos e instituições oficiais de ensino da rede } \\
\text { municipal }\end{array}$ & 1 & 6 & 7 & 4 \\
\hline $\begin{array}{l}\text { Autorizar, credenciar, supervisionar e } \\
\text { avaliar as instituições de ensino integrantes do } \\
\text { SME }\end{array}$ & 1 & 6 & 6 & 3 \\
\hline Baixar normas complementares & 1 & 4 & 7 & 2 \\
\hline $\begin{array}{l}\text { Exercer ação redistributiva em relação } \\
\text { às escolas }\end{array}$ & 1 & 0 & 6 & 7 \\
\hline $\begin{array}{l}\text { Elaborar e assegurar a valorização dos } \\
\text { profissionais de educação, através de Plano de } \\
\text { Carreira }\end{array}$ & & 3 & 1 & 2 \\
\hline $\begin{array}{l}\text { Elaborar e executar os planos } \\
\text { educacionais }\end{array}$ & & 6 & 3 & \\
\hline $\begin{array}{l}\text { Oferecer a educação infantil em } \\
\text { creches e pré-escolas e com prioridade o } \\
\text { ensino fundamental }\end{array}$ & & 0 & 1 & \\
\hline $\begin{array}{l}\text { Definir com o estado e a União um } \\
\text { regime de colaboração na oferta da educação } \\
\text { infantil e do ensino fundamental }\end{array}$ & & 3 & 0 & \\
\hline
\end{tabular}

Quadro 1 - Principais incumbências dos Sistemas Municipais de Ensino Microrregiões da Amai, Amnoroeste e Amosc

Fonte: legislação municipal dos municípios pesquisados 
De acordo com os dados do quadro, afora as cinco primeiras incumbências, as demais, embora constem na LDB, foram referidas com menor frequência, o que pode ser um indicativo de certa falta de sintonia com o texto da lei nacional.

De modo geral, aspectos como organização, número de seções e temas das principais seções revelam importante semelhança entre as leis municipais examinadas. $\mathrm{Na}$ maioria das leis prepondera a apresentação dos princípios da educação, da organização do SME, da gestão democrática do ensino público e dos níveis e as modalidades de educação e ensino.

No tocante à gestão educacional, por exemplo, todos os documentos abordam o tema em nível de rede e de escola, com destaque à participação da sociedade e dos órgãos competentes na elaboração e organização da proposta curricular, bem como nos processos administrativos e financeiros. Destacam-se o planejamento, o acompanhamento, a fiscalização e a avaliação com participação da comunidade escolar e local, através dos conselhos escolares ou equivalentes, ainda que careçam referências que apontem para medidas mais concretas de reforço à participação.

Outro exemplo diz respeito ao regime de colaboração. Em alguns casos, aparecem seções próprias que abordam o tema e, dentre esses casos, algumas leis trazem certo detalhamento acerca do mecanismo, embora insuficiente para superar 0 tom generalista no trato da questão. Como se sabe, o tema é complexo e se conserva pouco preciso em nível nacional, tendo mobilizado, inclusive, boa parte dos debates da Conferência Nacional de Educação (CONAE) de 2010.

Esse breve retrato geral da organização dos documentos permite-nos dizer, por um lado, que as leis dos sistemas municipais pesquisados correspondem a um conjunto de âmbitos sobre os quais a legislação nacional determina posicionamento municipal. Por outro, que em virtude das recorrentes semelhanças entre elas, são reforçadas as possibilidade de a maioria dos municípios não ter optado por um processo de construção que desaguasse em propostas próprias, nascidas do exercício de problematização da realidade educacional local.

No limite das consequências dessa frágil problematização, devemos considerar a possibilidade de os sistemas institucionalizados pouco alterarem a realidade 
educacional do município, questão que buscamos explorar com base na leitura que fazem dirigentes municipais de educação acerca do campo da prática.

A esse respeito, embora não haja unanimidade entre os depoentes, prepondera o reconhecimento de que houve mudanças na educação com a institucionalização do SME, o que sinaliza positivamente para uma das finalidades de um sistema próprio: a transformação da realidade, nomeadamente a educacional (SAVIANI, 2000; SARMENTO, 2005). Os dirigentes realçam, por exemplo, o alargamento da autonomia municipal como a principal mudança ocorrida a partir da institucionalização do SME.

Quando convidados a apontar os obstáculos enfrentados, as respostas dos depoentes revelam que as frágeis condições de sustentabilidade do regime de colaboração com o governo estadual, a fragilidade financeira associada à falta de planejamento dos investimentos e a escassez de recursos humanos constituem os três maiores empecilhos à organização e implementação do SME. O Quadro 2 sistematiza os obstáculos segundo o critério de frequência nas respostas, por microrregião:

\begin{tabular}{|l|c|c|c|c|}
\hline \multicolumn{1}{|c|}{ Obstáculo } & Amai & Amnoroeste & Amosc & Frequência \\
\hline $\begin{array}{l}\text { A sustentabilidade de um regime de } \\
\text { colaboração com o estado }\end{array}$ & 3 & 1 & 8 & $85,7 \%$ \\
\hline $\begin{array}{l}\text { A fragilidade financeira associada à falta } \\
\text { de planejamento dos municípios }\end{array}$ & 1 & 1 & 6 & $57,1 \%$ \\
\hline $\begin{array}{l}\text { A escassez de recursos humanos para } \\
\text { atuação nas áreas técnicas e } \\
\text { pedagógicas }\end{array}$ & - & - & 8 & $57,1 \%$ \\
\hline $\begin{array}{l}\text { Distanciamento entre a estrutura } \\
\text { administrativa e a população }\end{array}$ & 1 & 1 & 5 & $50 \%$ \\
\hline $\begin{array}{l}\text { Limitações para exercer as funções de } \\
\text { normatização legal complementar }\end{array}$ & 2 & - & 5 & $50 \%$ \\
\hline
\end{tabular}

Quadro 2 - Obstáculos à organização e implementação do SME dos municípios

da Amai, Amnoroeste e Amosc

Fonte: elaborado pelos pesquisadores com base nos questionários 
Com base nos dados do Quadro 2, constatamos que a fragilidade do regime de colaboração com o estado constitui, na leitura dos dirigentes, o maior obstáculo à organização e implementação dos SME. Embora o tema tenha merecido pouca atenção na legislação examinada, entendemos que a defesa dos interesses e necessidades locais, acentuada pelos depoentes, contribui para demarcar posição dos municípios sobre esse regime. Até porque, como uma questão em aberto, o regime de colaboração continua sendo um tema polêmico, merecedor de discussões "acerca dos condicionantes políticos que encerram um processo intencional de interrelacionamento entre esses sistemas, especialmente se considerarmos o modelo competitivo que tem presidido este processo." (NARDI, 2006, p.2).

Com frequência semelhante e significativa, também figuram obstáculos relativos ao financiamento, ao planejamento e a influência de interesses políticos. No campo do financiamento, as respostas acusam que para os municípios das microrregiões da Amai e da Amnoroeste os recursos disponíveis atendem, plena ou satisfatoriamente, as necessidades. Já para os municípios da microrregião da Amosc, a maior da amostra, os recursos disponíveis são considerados satisfatórios para 78 \% e insuficientes para $22 \%$ dos respondentes.

Com relação à aplicação dos recursos da educação, 64\% dos respondentes das três microrregiões destacaram que o procedimento é plenamente realizado, enquanto $36 \%$ consideraram seus planejamentos superficiais, com reflexos na gestão e no provimento das condições de oferta da educação no município.

Entre os dirigentes que declararam haver planejamento no município, figuram argumentos de que ocorre aplicação de recursos em educação para além dos $25 \%$ e de forma isonômica para todos os níveis da educação, além do aporte de mais recursos para atender ao planejado. Menos frequentes foram os argumentos de que 0 planejamento garante a correta aplicação dos recursos e que ações de maior custo sejam efetivamente executadas.

Já em relação aos que classificam o planejamento da aplicação dos recursos vinculados à educação como superficial, as justificativas são: frágil articulação entre conselhos, comunidade e administração; preponderância de ações decorrentes de 
pedidos pontuais; frágil cumprimento do planejamento anual; e alterações de prioridades motivadas por demandas não planejadas.

A preponderância dos interesses políticos foi fator enfatizado por $24 \%$ dos dirigentes e, com maior frequência, por respondentes da microrregião da Amosc. Embora essa interferência também ocorra nos municípios maiores, há certo consenso acerca da sua recorrência e dos seus reflexos nos municípios menores. Por extensão, a descontinuidade das políticas educacionais, destacada por $12 \%$ dos municípios, foi associada à prática de interesses alheios aos interesses coletivos.

Como aspectos favoráveis à organização e implementação dos SME, oS depoentes referiram a maior autonomia para praticar atos pedagógicos $\mathrm{e}$ administrativos de interesse local e a desburocratização dos serviços. A primeira vantagem foi a mais importante para $50 \%$ dos respondentes e a segunda para $28,8 \%$ deles.

Questionados sobre a melhor demarcação dos níveis em que o município deve atuar, haja vista possibilidade de maior focalização e precisão do atendimento educacional nas áreas de competência, as respostas dos dirigentes acusam que as condições de atuação municipal foram alteradas. Para $20 \%$ dos depoentes a medida favoreceu satisfatoriamente a atuação municipal na educação infantil e no ensino fundamental. Já os $80 \%$ restantes julgam ter ocorrido melhoras evidentes nas condições.

O regime de colaboração, já referido nesta análise, ganhou novo enfoque quando da abordagem das condições favoráveis à organização e implementação do SME. Com o propósito de levantar as medidas que traduzem colaboração entre os diferentes sistemas de ensino, verificamos que para $57,2 \%$ dos respondentes o planejamento foi uma das medidas operadas. Outros $35,7 \%$ acreditam ocorrer regime de colaboração na divisão de encargos, como na distribuição proporcional de responsabilidades na oferta do ensino fundamental. Apenas $7,1 \%$ dos dirigentes consideram que o regime de colaboração entre as esferas não existe efetivamente, o que tem sobrecarregado os municípios em demasia. 
Todos os dirigentes municipais consultados admitem que a gestão educacional do município passou por transformações. Entre os respondentes, 57\% julgam terem sido algumas as transformações e $43 \%$ referem significativas transformações. Os dados indicam, ainda, que $64,3 \%$ dos dirigentes acreditam que ocorreram avanços na democratização da gestão, $28,6 \%$ entendem que foram muitos os avanços e apenas 7,1\% dizem não ser possível afirmar a ocorrência de avanços nesse campo.

Em suma, esse conjunto de aspectos e suas frequências, apesar da existência de fragilidades como as já listadas, parecem-nos representativos de condições que podem ser fios condutores para avanços na implementação dos SME. De modo geral, a revista a essas condições e aos obstáculos, indica-nos que a implementação desses sistemas é interferida por fatores locais e fatores externos de importante repercussão no campo da educação.

Já no tocante às expectativas de desenvolvimento educacional nutridas pelos governos municipais, a partir do sistema próprio de ensino, encontramos no Quadro 3 o seu agrupamento em quatro eixos.

\begin{tabular}{|c|c|c|c|}
\hline Eixo & Amai & Amonoroeste & Amosc \\
\hline \multirow{4}{*}{$\begin{array}{l}\text { Qualificação da } \\
\text { educação escolar }\end{array}$} & $\begin{array}{l}\text { Melhoria } \\
\text { na qualidade de } \\
\text { ensino e do IDEB }\end{array}$ & & $\begin{array}{ll} & \text { Melhoria do } \\
\text { IDEB }\end{array}$ \\
\hline & $\begin{array}{l}\text { Melhor } \\
\text { andamento da } \\
\text { educação, } \\
\text { buscando } \\
\text { qualidade do } \\
\text { ensino }\end{array}$ & & \begin{tabular}{l}
\multicolumn{1}{c}{ Maior } \\
qualidade do ensino- \\
aprendizagem, com \\
construção de \\
espaços e ambientes \\
adequados
\end{tabular} \\
\hline & & & $\begin{array}{l}\text { Promover } \\
\text { meios de melhorar o } \\
\text { rendimento dos } \\
\text { alunos }\end{array}$ \\
\hline & $\begin{array}{l}\text { Erradicaçã } \\
\text { o do }\end{array}$ & & \\
\hline
\end{tabular}




\begin{tabular}{|c|c|c|c|}
\hline \multirow{3}{*}{ Formação geral } & analfabetismo & & \\
\hline & $\begin{array}{l}\text { Universali } \\
\text { zação do ensino } \\
\text { obrigatório }\end{array}$ & & $\begin{array}{l}\text { Atender a } \\
\text { todos as crianças em } \\
\text { idade escolar. }\end{array}$ \\
\hline & $\begin{array}{l}\text { Formação } \\
\text { humanística } \\
\text { cientifica e } \\
\text { tecnológica }\end{array}$ & $\begin{array}{l}\text { Garantir ao } \\
\text { educando o acesso e } \\
\text { a permanência numa } \\
\text { escola de qualidade, } \\
\text { assegurando a } \\
\text { formação de sua } \\
\text { personalidade, de } \\
\text { sua cidadania e do } \\
\text { conhecimento }\end{array}$ & \\
\hline \multirow[t]{2}{*}{$\begin{array}{l}\text { Organização e } \\
\text { funcionamento da } \\
\text { educação escolar }\end{array}$} & $\begin{array}{l}\quad \text { Organizar } \\
\text { melhor e } \\
\text { articular à } \\
\text { realidade do } \\
\text { município }\end{array}$ & & $\begin{array}{l}\text { Respeito à } \\
\text { realidade local. }\end{array}$ \\
\hline & $\begin{array}{l}\text { Progressiv } \\
\text { a ampliação do } \\
\text { tempo de } \\
\text { permanência na } \\
\text { escola, do aluno } \\
\text { de ensino } \\
\text { fundamental }\end{array}$ & & \\
\hline & $\begin{array}{l}\text { Promoção } \\
\text { de decisões mais } \\
\text { rápidas e justas, } \\
\text { tomadas junto } \\
\text { com os } \\
\text { profissionais da } \\
\text { educação }\end{array}$ & & $\begin{array}{l}\text { Oportunidade } \\
\text { de definição de } \\
\text { estratégias com a } \\
\text { participação de } \\
\text { conselhos }\end{array}$ \\
\hline & & & $\begin{array}{l}\text { Valorização } \\
\text { dos profissionais da } \\
\text { educação }\end{array}$ \\
\hline & & & $\begin{array}{l}\text { Autonomia } \\
\text { para a gestão de }\end{array}$ \\
\hline
\end{tabular}




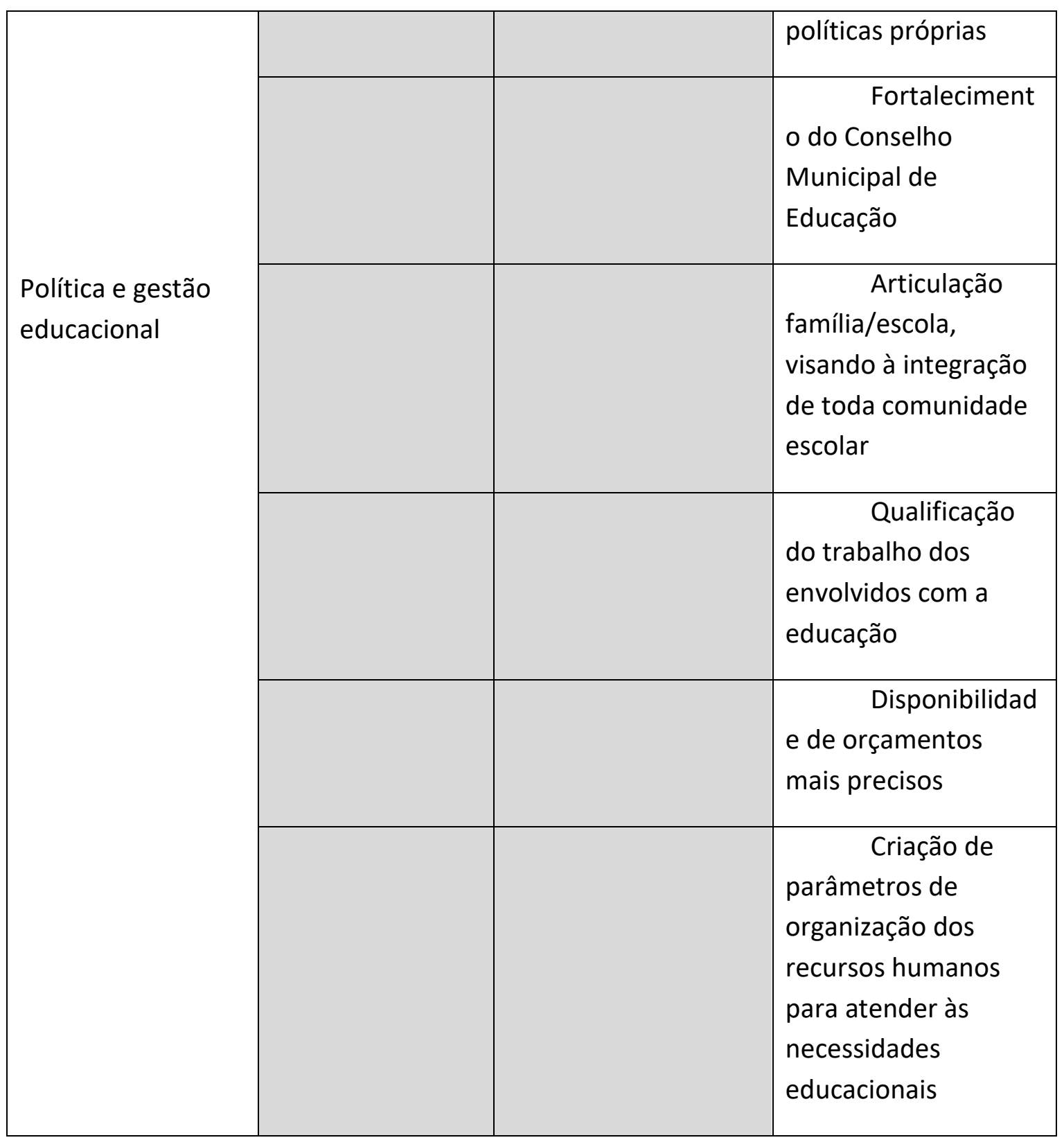

Quadro 3 - Expectativas de desenvolvimento educacional nutridas pelos governos municipais com a implementação do SME -microrregiões da Amai, Amnoroeste e Amosc

Fonte: elaborado pelos pesquisadores com base nos questionários

Os dados do Quadro 3 evidenciam, inicialmente, um cenário diverso. Enquanto nos municípios da Amai preponderam expectativas em relação à formação geral da população, na microrregião da Amosc sobressaem as de transformações no campo da política e da gestão educacional. Já na microrregião da Amnoroeste a expectativa comum é a garantia do acesso e permanência do educando em uma escola pública de qualidade, expectativa esta relacionada ao eixo da formação geral. 
Em relação ao eixo qualificação da educação escolar, a tônica das expectativas é o rendimento escolar, com destaque para a melhoria do Índice de Desenvolvimento da Educação Básica (IDEB), sugerida como expressão de qualificação da educação escolar da rede municipal.

O eixo formação geral é o que evidência maior aproximação entre as expectativas manifestadas pelos dirigentes. A universalização do ensino obrigatório e a formação para a cidadania constituem o foco dos posicionamentos dos respondentes. Já em relação à organização e funcionamento da educação escolar, eixo cujas expectativas também foram expressivas, é a atenção à realidade local que ganha força. Ademais, essa posição já havia sido referida quando da menção das razões mobilizadoras da institucionalização do SME, embora a transformação dessa realidade não tenha recebido idêntica atenção por partes dos dirigentes.

Por fim, no que concerne ao eixo política e gestão educacional, o conjunto e a origem das expectativas levantadas revelam um quadro curioso. Embora tenha sido o eixo com o maior número de expectativas, os resultados apontam sua concentração em uma única microrregião, a Amosc. Essa singularidade sugere sintonia dos dirigentes municipais com temas candentes da política e gestão educacional, ou mesmo uma leitura política das questões que atravessam a gestão municipal, o que não necessariamente concorda com dados levantados na legislação desses municípios.

Em síntese, podemos dizer que, relativamente às expectativas, a característica marcante é a diversidade. Os sujeitos da pesquisa nutrem expectativas variadas que, muito provavelmente, refletem tensões e angústias nascidas de suas experiências no campo da prática. Daí que a leitura que fazem projeta expectativas sobre o novo, inclusive sobre o SME.

\section{Considerações finais}

Tendo por base os documentos e informações levantadas, o trabalho destaca que a mobilização dos municípios pesquisados para organizar o SME relacionou-se, inicialmente, à necessidade de corresponder ao previsto na LDB e aos mínimos fixados 
pela lei nacional. Em face do motor dessa mobilização, os achados iniciais da pesquisa fortalecem a suspeita de que a maioria dos municípios, quando da elaboração e aprovação das suas leis, não tenha buscado observar mais atentamente a realidade e os desafios locais.

Em favor dessa leitura, pesa a constatação de uma significativa semelhança entre os conteúdos dos documentos examinados, muito embora tenham sido identificadas variações nas opções acerca da organização e gestão do SME, sobre as quais mereceram destaque os princípios e espaços ou mecanismos de gestão democrática do ensino público.

No entanto, contrariamente à inobservância dos municípios à realidade e aos desafios locais, sugerida pela base legal examinada, nos demais dados e informações levantados sobressai o reconhecimento de mudanças na organização e gestão da educação municipal, ocorridas com a institucionalização do SME, ainda que figurem leituras que não atestem transformações locais mais profundas.

Sugestivamente, esse reconhecimento reforça a possibilidade de os municípios trilharem o caminho da transformação da realidade municipal, de modo a promover a melhoria das condições locais e, portanto, maior compasso entre estas e as expectativas de desenvolvimento educacional. Aspectos como o alargamento da autonomia municipal no campo pedagógico, assente na institucionalização do SME, reforçam sobremaneira essa possibilidade.

A nosso ver, embora persistam obstáculos impostos pelos contextos internos e externos aos municípios, os resultados da pesquisa sugerem possibilidades concretas de enfrentamento dos desafios e de defesa aos projetos municipais de educação. Tanto a análise criteriosa dos condicionantes desses obstáculos como a disposição política de enfrentá-los nos parecem atitudes indispensáveis ao cumprimento da tarefa. 


\section{Referências}

AZEVEDO, J. M. L. de; SANTOS, A. L. F. dos. Influências do poder central no planejamento da educação dos municípios da região metropolitana do Recife. Educação \& Sociedade, Campinas, v.33, n. 119, p. 551-573, abr.-jun. 2012.

BOAVENTURA, E. A educação brasileira e o direito. Belo Horizonte: Nova Alvorada, 1997.

BRASIL. Ministério da Educação. Conselho Nacional de Educação. Parecer CEB/CNE no 30/2000. Brasília, DF, 12 de setembro de 2000. Disponível em: <http://portal.mec.gov.br/cne/arquivos/pdf/pceb030_00.pdf>. Acesso em: 18 jan. 2011.

BRASIL. Casa Civil. Lei no 9.394, de 20 de dezembro de 1996. Estabelece as diretrizes e bases da educação nacional. Brasília, DF, 1996. Disponível em: <http://www.planalto.gov.br/ccivil_03/Leis/L9394.htm>. Acesso em: 17 out. 2010.

BRASIL. Casa Civil. Constituição da República Federativa do Brasil de 1988. Brasília, DF, $1988 . \quad$ Disponível em: <http://www.planalto.gov.br/ccivil_03/Constituicao/Constituicao.htm>. Acesso em: 17 out. 2010.

CURY, R.J. Sistema nacional de educação: desafio para uma educação igualitária e federativa. Educação \& Sociedade, Campinas, v.29, n. 105, p.1187-1209, set.-dez. 2008.

NARDI, E. L. Sistemas municipais de ensino e o regime de colaboração entre estado e municípios: por onde vamos? In: WERLE, F. O. (Org.). Sistema municipal de ensino e regime de colaboração. ljuí: Unijuí, 2006. p.57-81.

ROMÃO, J. E. Sistemas municipais de educação: a lei de diretrizes e bases (LDB) e a educação no município. São Paulo: Ed. e Livraria Instituto Paulo Freire, 2010.

SARMENTO. D. C. Criação dos sistemas municipais de ensino. Educação \& Sociedade, Campinas, v.26, n. 93, p.1363-1390, dez. 2005. 
SAVIANI, D. Educação brasileira: estrutura e sistema. Campinas: Autores Associados, 2000.

SAVIANI, D. Sistemas de ensino e planos de educação: o âmbito dos municípios. Educação \& Sociedade, Campinas, v.20, n.69, p. 119-136, dez. 1999.

SOUZA, D. B. de; RAMOS, M. N.; DELUIZ, N. Cobertura municipal da educação profissional via regime de colaboração: uma prática possível? Ensaio, Rio de Janeiro, v.15, n.54, p. 29-52, jan.-mar. 2007.

VIEIRA, S. L. Poder local e educação no Brasil: dimensões e tensões. Revista Brasileira de Política e Administração da Educação, Porto Alegre, v.27, n.1, p.123-133, jan.-abr. 2011.

WERLE, F. O. C.; THUM, A. B.; ANDRADE, A. C de. Sistemas municipais de ensino no Rio Grande do Sul: uma contribuição para as políticas educacionais. Revista Brasileira de Política e Administração da Educação, Porto Alegre, v. 26, n. 2, p.377-393, mai.-ago. 2010.

Enviado em Setembro/2013 Aprovado em Fevereiro/2014 